\title{
ANALISIS NILAI SOSIAL DALAM KUMPULAN CERPEN ROBOHNYA SURAU KAMI KARYA A.A. NAVIS
}

\author{
Isti Qomala Dewi, Sarwit Sarwono, dan Emi Agustina \\ Program Studi Pendidikan Bahasa Indonesia \\ Jurusan Pendidikan Bahasa dan Seni \\ FKIP Universitas Bengkulu \\ gomaladewii@gmail.com
}

\begin{abstract}
Abstrak
Tujuan penelitian ini adalah mendeskripsikan nilai sosial yang terdapat pada kumpulan cerpen Robohnya Surau Kami karya A.A Navis. Novel ini diterbitkan oleh PT. Gramedia Pustaka Utama Jakarta, November 2010 pada cetakan ketujuh belas. Penelitian ini menggunakan teori sosiologi sastra. Hasil penelitian menunjukkan bahwa nilai sosial yang terdapat dalam kumpulan cerpen Robohnya Surau Kami yaitu: (1). Nilai sosial yang mencerminkan hubungan manusia dengan Tuhan (MH) meliputi: a). Mengakui adanya Tuhan, b). Berdoa dan beribadah, c). Bersyukur, d). Tawakal. (2). Nilai sosial yang mencerminkan hubungan manusia dengan sesama manusia (MM) meliputi: a). Tolong menolong, b). Menasehati, c). Kasih sayang, d). Minta maaf, e). Sikap saling menghormati, f). Sikap tanggung jawab. (3). Nilai sosial yang mencerminkan hubungan manusia dengan alam sekitar (MA) yaitu: a). Menghargai Alam. (4). Nilai sosial yang mencerminkan hubungan manusia dengan diri sendiri (MK) meliputi: a). Bekerja keras, b). Sabar, c). Tegar. Adapun kesimpulan dalam penelitian ini yaitu bahwa kehidupan masyarakat Minang Kabau dalam kumpulan cerpen Robohnya Surau Kami memiliki nilai-nilai sosial yang tinggi.
\end{abstract}

\section{Kata Kunci: Analisis, nilai sosial, Robohnya Surau Kami}

\begin{abstract}
The purpose of this study to descriptive the social value contained in a collection of short stories Robohnya Surau Kami creation A.A. Navis. This research is based sociology of literature, and published by PT. Gramedia Library Jakarta, November 2010 in seventeenth print. The results showed that the social contained in a collection of short stories Robohnya Surau Kami include: (1). Social values that reflect the human relationship with $\mathrm{God}(\mathrm{MH})$ include: a). Acknowledge existence of a god, b). Pray and worship, c). Grateful, d). Tawakal. (2). Social values that reflect human relationship with fellow human beings (MM) include: a). Mutual help, b). Advise, c). Effection, d). sorry, e). Mutual respect, f). Attitude of responsibility. (3). Social values that reflect human relationship with the natural surroundings (MA) include: a). Appreciate nature and for the (4). Social values that reflects the human relationship with oneself include: a). work hard, b). Patient, c). Tough. Conclusion in this research that is, people's lives of Minanf Kabau in a collection of short stories Robohnya Surau Kami which has a high social value.
\end{abstract}

Keyword: Analysis, social values, Robohnya Surau Kami 


\section{PENDAHULUAN}

Kumpulan Cerpen Robohnya Surau Kami merupakan karya A.A. Navis yang paling fenomenal, karena isi dari cerpen tersebut masih relevan dengan masa kini meski zaman telah berubah. Di dalam kumpulan cerpen Robohnya Surau Kami banyak memuat nilai sosial. Salah satunya adalah cerpen yang berjudul Robohnya Surau Kami. Cerpen ini menceritakan tentang kehidupan seseorang yang taat beribadah dan menyembah kepada Tuhan selama hidupnya, namun ia harus dimasukkan ke dalam neraka. Hal ini bagi Navis adalah hal yang amat egois karena Tuhan tidaklah suka pada mereka yang malas bekerja dan tidak bertanggung jawab atas amanah yang sudah diberikan Tuhan.

Membaca dan memahami suatu karya sastra merupakan suatu langkah dari kegiatan apresiasi karya sastra. Karya sastra juga sebagai interpretasi kehidupan yang melukiskan kehidupan manusia yang terdapat dalam masyarakat. Segala persoalan yang tertuang dalam karya sastra dituliskan oleh pengarangnya. Meskipun demikian tidak jarang kita jumpai adanya karya sastra yang ditulis oleh pengarang yang berbeda tetapi memiliki hubungan antar karya sastra tersebut. Seperti yang dikemukakan oleh Mursal Esten (1984:12) bahwa cerpen adalah pengungkapan suatu pesan yang hidup dari fragmen kehidupan manusia. Dalam cerpen terjadi lintasan dari secercah kehidupan manusia dalam satu kesatuan waktu.

Sosiologi sastra merupakan konsep yang bertolak dari orientasi kepada semesta, Endraswara (2003:78) namun bisa juga bertolak dari orientasi kepada pengarang dan pembaca. Menurut konsep sosiologi sastra, karya sastra dilihat hubungannya dengan kenyataan, sejauh mana karya sastra itu mencerminkan kenyataan. Kenyataan di sini mengandung arti yang cukup luas, yakni segala sesuatu yang berada di luar karya sastra dan yang diacu oleh karya sastra.

Sosiologi sastra menaruh perhatian pada aspek dokumen sastra, dengan landasan suatu pandangan bahwa sastra merupakan gambaran atau potret fenomena sosial. Pada hakikatnya, fenomena sosial itu bersifat konkret, terjadi di sekeliling kita sehari-hari, bisa diobservasi, difoto, dan didokumentasikan.

Oleh karena itu, karya sastra yang lahir di tengah-tengah masyarakat merupakan hasil pengungkapan jiwa pengarang tentang kehidupan, peristiwa, serta pengalaman hidup yang telah dihayatinya.

Cerpen yang akan diteliti ini adalah kumpulan cerpen yang berjudul Robohnya Surau Kami karya A.A. Navis. Cerpen yang merupakan karya pertama A.A. Navis ini juga sekaligus melambungkan namanya sebagai penulis atau sastrawan. Cerpen ini diterbitkan pertama kali pada tahun 1955. Cerpen yang menjadi best seller nasional ini telah dicetak sebanyak tujuh belas kali bersama judul-judul cerpen lain karya A.A. Navis.

Adapun, kumpulan cerpen Robohnya Surau Kami Navis megkritik kepada mereka yang taat beribadah namun melalaikan kewajiban yang lain. Dalam cerpen ini A.A. Navis mengkritik juga pada mereka yang ikut-ikutan tapi tidak tahu-menahu apa yang diikutinya. A.A. Navis juga berpendapat dalam amanatnya bahwa ibadah itu bukan hanya sekedar memuji dan menyembah Tuhan melainkan harus juga peduli pada lingkungan sekitar.

Alasan mengambil kumpulan cerpen Robohnya Surau Kami ini, penulis ingin memperlihatkan kepada pembaca atau penikmat sastra bahwa dalam karya sastra terdapat nilai-sosial. Karena, karya sastra di dalam kumpulan cerpen Robohnya Surau Kami merupakan cerminan kehidupan masyarakat. 


\section{METODE}

Penelitian ini menggunakan pendekatan sosiologi sastra, yaitu memasalahkan karya sastra itu sendiri yang menjadi pokok penelaahannya. Menurut Wellek dan Warren (1989: 111), mengklasifikasikan beberapa teori sosiologi sastra sebagai berikut: (1) sosiologi pengarang sebagai penghasil sastra, (2) sosiologi karya sastra, tujuan serta hal-hal yang tersirat dalam karya sastra itu sendiri dan yang berkaitan dengan masalah sosial, (3) permasalahan pembaca dan dampak sosial karya sastra.

Langkah yang dilakukan peneliti terlebih dahulu memahami keseluruhan nilai-nilai sosial yang terkandung dalam kumpulan cerpen Robohnya Surau Kami karya AA. Navis.

Objek penelitian ini terfokus pada nilai-nilai sosial yang mencerminkan kehidupan masyarakat pada umumnya. Dengan demikian, peneliti berharap nilai sosial tersebut dapat tergali dan dapat bermanfaat di dalam kehidupan bermasyarakat pada umumnya.

\section{HASIL PENELITIAN DAN PEMBAHASAN}

Hasil penelitian tentang nilai-nilai sosial Sumatera khususnya Minangkabau dalam kumpulan cerpen Robohnya Surau Kami karya A.A Navis meliputi: (a) nilai-nilai sosial dalam konteks hubungan manusia dengan Tuhan (MH); (b) hubungan manusia dengan sesama manusia (MM); (c) hubungan manusia dengan alam sekitar (MA); (d) hubungan manusia dengan diri sendiri (MK)

\section{Nilai-nilai sosial yang mencerminkan Hubungan antara Manusia dengan Tuhan.}

Nilai-nilai sosial yang mencerminkan hubungan antara manusia dengan Tuhan (MH) yang dideskripsikan dalam kumpulan cerpen Robohnya Surau Kami mencakup nilai: beriman, berdoa, bersyukur, dan tawakal. Tokoh Kakek beriman kepada kebesaran Tuhan dengan cara mengakui adanya Tuhan, sebagai implementasi iman akan kebesaran Tuhan atas seluruh hidup manusia. Tokoh Kakek memohon kepada Tuhan agar bisa masuk surga dalam bentuk beribadah dan berdoa kepada Tuhan. Adapun Sebagai perwujudan kebesaran Tuhan, ibadah yang dilakukan manusia adalah selalu ingat dan berdoa kepada Tuhan Yang Maha Tunggal. Tujuan dari itu semua tidak lain adalah untuk mencapai kebahagiaan dunia dan di akhirat.kutipan tersebut terdapat dalam cerpen Anak Kebanggan. Tokoh Kakek dalam cerpen Robohnya Surau Kami dan Tokoh Ayah dalam cerpen Datang Dan Perginya selalu berserah diri kepada Tuhan atas segala hidupnya dan berusaha semampunya untuk memperbaiki hidupnya karena segala kehidupan di dunia telah di atur oleh Tuhan.

Pada cerpen Robohnya Surau Kami tersebut menjelaskan sikap kakek yang sudah menyerahkan dirinya kepada Tuhan, karena kakek percaya bahwa Tuhan akan mengasihi orang yang sabar dan tawakal.. Kutipan yang senada juga terdapat pada kutipan cerpen Datangnya dan Perginya menjelaskan bahwa tokoh ayah setelah bertaubat kemudian menyerahkan segalanya kepada Allah SWT. Dari sini dapat diketahui bahwa tokoh tersebut benar-benar berpasrah diri kepada Tuhan dan kemudian diwujudkan dengan hal-hal yang positif yaitu jalan yang diridhoi oleh Allah SWT.

\section{Nilai sosial yang mencerminkan Hubungan antara Manusia dengan Sesama Manusia}

Sepanjang hidupnya, manusia selalu berinteraksi dengan manusia lain di sekitarnya. Hal ini sesuai dengan kodrat manusia sebagai makhluk sosial yang senantiasa membutuhkan kehadiran manusia lain. Antara manusia satu dengan 
yang lainnya terjalin suatu hubungan karena adanya rasa saling membutuhkan dan saling ketergantungan. Pendapat yang berterima dalam khalayak adalah mustahil apabila manusia dapat hidup secara individu tanpa bantuan manusia lain. Dalam interaksi antar sesama nilai ini disebut nilai sosial. Maka di dalam kumpulan cerpen Robohnya Surau Kami terdapat nilai-nilai sosial tersebut: cerpen Angin dari Gunung, Nasihat nasihat, Menanti Kelahiran, Datang dan Perginya, dan Topi Helm.

\section{Nilai-nilai Sosial yang Mencerminkan Hubungan antara Manusia dengan Alam}

Sekitar kita pasti ada hubungannya dengan alam yang saling mempengaruhi perilaku manusia yang memanfaatkan dan karena mempengaruhi alam untuk keperluan hidupnya. Alam memberikan banyak manfaat bagi manusia, maka sudah sewajarnya manusia mencintai alam. Selain berbagai manfaat, alam juga harus dihargai. Alam adalah sahabat manusia yang boleh dimanfaatkan tetapi tetapi tidak dieksploitasi. Pemanfaatan alam haruslah diimbangi dengan menghargai alam, dalam kumpulan cerpen Robohnya Surau Kami ini diwujudkan dengan cara melukiskan keindahan alam yang ada disekitarnya, sebagaimana pada kutipan yang ada di dalam cerpen Angin dari Gunung.

\section{Nilai-nilai Moral yang Mencerminkan Hubungan antara Manusia dengan Diri Sendiri.}

Antara manusia dengan dirinya sendiri kerap terjadi pergulatan batin dalam menghadapi suatu permasalahan hidup. Pergulatan batin berupa pemikiran menghasilkan sikap. Dalam sikap atau tindakan seorang tokoh pada kumpulan cerpen, ada nilai-nilai sosial yang dapat di interpretasikan. Nilai sosial yang mencerminkan hubungan antara manusia dengan dirinya sendiri dalam kumpulan cerpen Robohnya Surau Kami yang terdapat dalam cerpen Pada Pembotakan Terakhir dan cerpen Dari Masa Ke Masa.

\section{PENUTUP \\ Kesimpulan}

Berdasarkan hasil penelitian yang telah penulis lakukan dapat diambil kesimpulan bahwa kehidupan A.A. Navis di masyarakat Minang Kabau dalam kumpulan cerpen Robohnya Surau Kami memiliki nilai-nilai sosial yang tinggi, adapun nilai nilai sosial yang terdapat dalam masyarakat Minang Kabau yaitu : adanya hubungan manusia dengan Tuhan, hubungan manusia dengan sesama manusia, hubungan manusia dengan alam sekitar, dan adanya hubungan manusia dengan dirinya sendiri.

\section{Saran}

a. Kepada pembaca diharapkan agar nilai-nilai sosial dan budaya yang terdapat dalam kumpulan cerpen Robohnya Surau Kami dapat menjadikan perenungan dalam menjalani hidup, sehingga nantinya dapat dijadikan pedoman dalam menentukan sikap yang harus ditempuh.

b. Kepada mahasiswa diharapkan agar kumpulan cerpen Robohnya Surau Kami tersebut dapat digunakan sebagai bahan pelajaran dan kajian ilmiah dalam rangka pelestarian khasanah kesusastraan Indonesia. Selanjutnya, nilai-nilai moral dan budaya yang terkandung di dalam kumpulan cerpen Robohnya Surau Kami pada khususnya dan karya sastra cerpen pada umumnya, diharapkan dapat diresapi dan diterapkan dalam kehidupan seharihari. 
DAFTAR PUSTAKA

Endraswara, Suwardi. 2003. Metodologi Penelitian Sosiologi Sastra.Yogyakarta: PT Buku Seru.

Esten, Mursal. 1984. Kesustraan Pengantar Teori dan Sejarah. Bandung: Angkasa.
Navis, A.A. 2010. Robohnya Surau Kami. Cetakan ketujuh belas. Jakarta: PT Gramedia Pustaka Utama.

Werren, Wellek. 1989. Teori Kesusastraan. Jakarta: PT Gramedia. 